llona Cwięczek

Agnieszka Lipieta

\title{
INNOVATIVE MECHANISMS IN A PRIVATE OWNERSHIP ECONOMY WITH A FINANCIAL MARKET*
}

\section{Abstract}

Let a private ownership economy with a financial market be given. In this economy, innovations in Schumpeter's sense of the term can be modeled by the use of the Arrow and Debreu topological apparatus. This set-up reveals the impact of the relationship between the financial and the real markets in the economy on innovation.

The paper distinguishes and models innovations and different types of innovative mechanisms revealed within Schumpeterian evolution. Following Hurwicz's approach to modeling economic mechanisms, the main results take the form of mathematical theorems interpreted in the language of economics.

Keywords: Schumpeterian evolution, mechanisms, designing mechanisms, economy with a financial market.

JEL Classification: C60, D41, D50, O10, O31.

\section{Introduction}

This paper extends the research programme of modeling the Schumpeterian vision of the economic development (see e.g. Schumpeter

Ilona Ćwięczek, Cracow University of Economics, Faculty of Finance and Law, Department of Mathematics, Rakowicka 27, 31-510 Kraków, Poland, e-mail: cwieczei@uek.krakow.pl

Agnieszka Lipieta, Cracow University of Economics, Faculty of Finance and Law, Department of Mathematics, Rakowicka 27, 31-510 Kraków, Poland, e-mail: alipieta@uek.krakow.pl

* The author acknowledge the support from research funds, granted to the Faculty of Finance and Law of the Cracow University of Economics, within the framework of the subsidy for the maintenance of research potential. 
1912) in the Arrow-Debreu set-up (see Debreu 1959) initiated by A. Malawski in the 1990s (see e.g. Malawski 1999).

J. Schumpeter distinguished five forms of change that characterise economic development:

1) the introduction of a new good,

2) the implementation of a new technology (method) into production,

3) the opening of a new market,

4) the conquest of a new source of supply of raw materials,

5) the re-organisation of any industry.

This five-part categorisation can be regarded as the classification of innovations (see Schumpeter 1912; Innovative Economy... 2013, Chapter 1). Schumpeter viewed innovation and innovators as the driving forces of economic development. On the other hand, according to the principle of creative destruction, innovating removes obsolete commodities, technologies and organisational structures from the markets. Hence, though they are essential to the long-term development of every economy, innovation can in the short run lead to negative effects for some economic agents. In his book (1912), Schumpeter also stresses the particular influence the financial sphere of the economy exerts on innovation, as easily accessible credit can initiate and intensify the processes of evolution as well as encourage a potential future innovator to begin to act. Readers will find some results of modeling the impact that the relationship between the real and financial sectors of the economy has on the innovation in (Ciałowicz \& Malawski 2011; Ćwięczek, Lipieta \& Malawski 2012; Innovative Economy 2013..., Chapters 2 and 3).

In this paper, innovations in Schumpeter's sense are analysed in a so-called private ownership economy with a financial market, which is an extension of the two-period financial economy with the production (see Magill \& Quinzii 2002), while the innovative processes are modeled as economics mechanisms as L. Hurwicz handled them (see e.g. Hurwicz \& Reiter 2006). This approach will enable us to stress the role the economy's financial sector plays in introducing innovations and to determine the relationship between signals sent by economic agents and their aims.

The paper consists of four parts. The next section defines the private ownership economy with a financial market. The third part models innovations in this economy, while the fourth part analyses innovative mechanisms in the economy with the financial market. 


\section{The Private Ownership Economy with a Financial Market}

The (micro) economic system under consideration describes the activities of market participants on the financial and commodity markets in two consecutive time intervals, called periods. The model of the economy presented here is a modification of a two-period financial economy with production (Magiil \& Quinzii 2002, pp. 329-56).

Time and uncertainty are described by an event tree, consisting of the initial period and the finite number of states of nature $s=1, \ldots, S(S \in \mathbb{N})$ in the next period $t=1$. Since the period $t=0$ is interpreted as the state of the nature of $s=0$, the number of all states is $S+1$.

In each state $s \in\{0,1, \ldots, S\}$ there are $\ell(\ell \in \mathbb{N})$ goods on the real markets. Therefore the commodity space is $\mathbb{R}^{\ell(S+1)}$, and the price vector of real commodities will be denoted $p=\left(p_{0}, p_{1}, \ldots, p_{S}\right) \in \mathbb{R}^{\ell(S+1)}$.

The financial market $F=\left(\mathbb{R}^{J}, q, V\right)$ is defined by the existence of $J$ basic securities (assets). A security $j, j \in\{1, \ldots, J\}$, can be purchased for price $q_{j}$ at date $t=0$ and sell in state $s \in\{1, \ldots, S\}$ at date $t=1$ to obtain payment $v_{s}^{j}$. Let $q=\left(q_{1}, \ldots, q_{J}\right) \in \mathbb{R}^{J}$ denote the vector of security prices at date $t=0$ while matrix $V=\left[v_{s}^{j}\right]$ for $s \in\{1, \ldots, S\}, j \in\{1, \ldots, J\}$, with their payment at date $t=1$. The row $V, s \in\{1, \ldots, S\}$, of matrix $V$ determines the payoff of all assets in state $s$ while column $V^{j}, j \in\{1, \ldots, J\}$, determines the payment of security $j$ in every state at date $t=1$. Let $z=\left(z_{1}, \ldots, z_{J}\right) \in \mathbb{R}^{J}$ denote a portfolio of securities. Then $q z=\sum_{j=1}^{j=J} q_{j} z_{j}$ means the price of the portfolio $z \in \mathbb{R}^{J}$ at date $t=0$, in turn $\tau_{s}=V_{s} z=\sum_{j=1}^{j=J} v_{s}^{j} z_{j}$ its payment (the income from the sale of the portfolio) in state $s \in\{1, \ldots, S\}$ at date $t=1$. In this way the purchase of a portfolio induces a stream of income $\tau^{1}=\left\{\tau_{1}, \ldots, \tau_{S}\right\} \in \mathbb{R}^{S}$ at date $t=1$. The collection:

$$
\langle V\rangle=\left\{\tau^{1} \in \mathbb{R}^{S}: \tau^{1}=V z \text { for some } z \in \mathbb{R}^{J}\right\}
$$

is called a set of contingent payments and describes the opportunities offered by the financial market. Since $J$ is the number of basic securities, the columns of matrix $V$ are linearly independent in space $\mathbb{R}^{S}(J \leq S)$. Therefore, $\operatorname{dim}\langle V\rangle=J$. We say that financial market $F$ is complete if and only if $\langle V\rangle=\mathbb{R}^{S}$. This means that any contingent payment can be obtained as the payment of a portfolio $z \in \mathbb{R}^{J}$. 
Let $W=\left[\begin{array}{c}-q \\ V\end{array}\right]$ denote the matrix of security prices at date $t=0$ and their payoffs at date $t=1$. The collection of all income streams priced by the financial market is denoted:

$$
\langle W\rangle=\left\{\tau=\left(\tau_{0}, \tau^{1}\right) \in \mathbb{R}^{S+1}: \tau=W z \text { for some } z \in \mathbb{R}^{J},\right.
$$

where $\tau_{0}=-q z$ and $\tau^{1}=V z$, and is called a market subspace. The set of all possible income transfers which can be obtained on the financial market is the subspace of $\mathbb{R}^{S+1}$ generated by the $J$ columns of matrix $W$. The set of all vectors that are orthogonal to each of the columns of matrix $W$ is called the space of state prices or the space of present-value vectors and is denoted:

$$
\langle W\rangle^{\perp}=\left\{\mu \in \mathbb{R}^{S+1}: \mu W=0\right\}=\left\{\mu \in \mathbb{R}^{S+1}: \mu \tau=\sum_{s=0}^{s=S} \mu_{s} \tau_{s}=0 \quad \forall \tau \in W\right\} .
$$

For the interpretation of vector $\mu=\left(\mu_{0}, \ldots, \mu_{s}\right) \in \mathbb{R}^{S+1}$ as a present-value vector it is convenient to assume that $\mu_{0}=1$. Then $\mu_{s}$, for $s \in(1, \ldots, S)$, is the present value (at date $t=0$ ) of one unit of income in state $s$ at date $t=1$. The market participants use the vector of state prices for discounting (at date $t=0)$ streams of income derived from date $t=1$. Let $\mu^{1}=\left(\mu_{1}, \ldots, \mu_{s}\right) \in \mathbb{R}^{s}$. By definition of space $\langle W\rangle^{\perp}$ the following is true: $q=\mu^{1} V$ and in particular $q_{j}=\sum_{s=1}^{s=S} \mu_{s} v_{s}^{j}$ for $j \in\{1, \ldots, J\}$. Thus, the price of asset $j$ at date $t=0$ is the sum of the discounted payments of that security. If the financial market is complete, the vector of present-value is uniquely determined.

In the economy under consideration, a finite number of consumers and producers (firms) operate. We assume the following:

1) financial market $F$ is complete;

$2)$ in a commodity-price space $\mathbb{R}^{\ell(S+1)}$, price vector $p=\left(p_{0}, p_{1}, \ldots, p_{S}\right) \in$ $\mathbb{R}^{\ell(S+1)}$ is given;

3) $A=\left\{a_{1}, \ldots, a_{m}\right\}, m \in \mathbb{N}$, is a set of consumers; for any consumer $a \in A$ :

a) $X^{a}=\left(X_{0}^{a}, \ldots, X_{S}^{a}\right) \subset \mathbb{R}_{+}^{\ell(S+1)}$ is a consumption set,

b) $u^{a}: X^{a} \rightarrow \mathbb{R}$ is a continuous and strongly increasing utility function defined on vector of consumption $x^{a}=\left(x_{0}^{a}, \ldots, x_{S}^{a}\right) \in X^{a}$,

c) $\omega^{a}=\left(\omega_{0}^{a}, \ldots, \omega_{S}^{a}\right) \in \mathbb{R}^{\ell(S+1)}$ is an initial endowment vector;

4) $B=\left\{b_{1}, \ldots, b_{n}\right\}, n \in \mathbb{N}$, is a set of producers (firms). For any producer $b \in B$ :

a) $Y^{b}=\left(Y_{0}^{b}, \ldots, Y_{S}^{b}\right) \subset \mathbb{R}^{\ell(S+1)}$ is a production set,

b) $y^{b}=\left(y_{0}^{b}, \ldots, y_{S}^{b}\right) \in Y^{b}$ is a feasible production plan (investment project); 
5) the ownership structure of firms is defined as private ownership, where consumers are the owners. Their participation in the financing of the firms is determined by the function $\theta \subset(A \times B) \times \mathbb{R}, \theta:(a, b) \rightarrow \theta^{a b} \in[0,1]$, satisfying: $\sum_{a \in A} \theta^{a b}=1$ for all $b \in B$.

Let $u=\left(u^{a}\right)_{a \in A}=\left(u^{a_{1}}, \ldots, u^{a_{m}}\right), \omega=\left(\omega^{a}\right)_{a \in A}=\left(\omega^{a_{1}}, \ldots, \omega^{a_{m}}\right)$ and $Y=$ $=\left(Y^{b_{1}}, \ldots, Y^{b_{n}}\right)$.

Definition 2.1. When the economic system has the following features, it is called an economy with private ownership and a financial market:

$-m$ consumers $(m \in \mathbb{N})$ and $n$ firms $(n \in \mathbb{N})$ operate on the financial and commodities markets in the two periods;

- the shareholders are consumers characterised by the utility functions $u^{a}: X^{a} \rightarrow \mathbb{R}$ and initial endowment $\omega^{a} \in \mathbb{R}^{\ell(S+1)}$;

- sets of production $Y^{b} \subset \mathbb{R}^{\ell(S+1)}$ for the firms are defined.

Such an economy will be denoted $\varepsilon_{F}=(u, \omega, Y, \theta, V)$.

The structure of economy $\varepsilon_{F}$ can be described as follows. At price vector $p \in \mathbb{R}^{\ell(S+1)}$, security prices $q \in \mathbb{R}^{J}$ and payoff matrix $V$, every producer takes such actions on the commodity market and on the financial market that allow it to maximise the present-value of their income stream. In turn, every consumer takes actions on the commodity markets and on the financial market to maximise their utility function on the set of budget constraints by the initial endowment vector $\omega^{a} \in \mathbb{R}^{\ell(S+1)}$.

The choice and realisation of investment project $y^{b}=\left(y_{0}^{b}, \ldots, y_{S}^{b}\right) \in Y^{b}$ depends on how the investment is financed. We assume that every firm can borrow without limits on the financial market at date $t=0$ and that it is responsible for repaying the debit at date $t=1$. At date $t=0$ the firm $b \in B$ realises the investment project $y_{0}^{b} \in \mathbb{R}^{\ell}$ at the vector of prices $p_{0} \in \mathbb{R}^{\ell}$ and purchases the portfolio $f^{b} \in \mathbb{R}^{J}$ at security prices $q \in \mathbb{R}^{J}$. The firm's income in this period is equal to $d_{0}^{b}=p_{0} y_{0}^{b}-q f^{b}$. In turn, at date $t=1$ and state $s \in\{1, \ldots, S\}$ firm $b$ receives its profit from the production plan at the vector of prices $p_{s}^{b} \in \mathbb{R}^{\ell}$ and sells portfolio $f^{b} \in \mathbb{R}^{J}$ at payoff matrix $V$. The income of firm $b$ in the state $s \in\{1, \ldots, S\}$ is equal to $d_{s}^{b}=p_{s} y_{s}^{b}+V_{s} f^{b}$. In this way we get the income stream $d^{b}=\left(d_{0}^{b}, \ldots, d_{S}^{b}\right) \in \mathbb{R}^{S+1}$ of firm $b$.

It is said that portfolio (financial policy) $f^{b} \in \mathbb{R}^{J}$ finances production plan $y^{b} \in Y^{b}$ if the income stream equations are fulfilled. The choice of this policy depends on how the investment is financed at date $t=0$. If $d_{0}^{b}>0$, then the investment (project) is financed by borrowing on the financial market. Firm $b$ 's action plan can be written as a pair $\left(y^{b}, f^{b}\right) \in Y^{b} \times \mathbb{R}^{J}$, where $f^{b}$ is the 
policy financing $y^{b}$. Every firm chooses action plan $\left(y^{b^{*}}, f^{b^{*}}\right)$ that maximises the present-value of the income stream $\mu d^{b}=\sum_{s=0}^{s=S} \mu_{s} d_{s}^{b}$ at the vector of state prices $\mu$. Let $\mu d^{b^{*}}=\max _{\left(y^{b}, f^{b}\right)} \mu d^{b}$ for all $\left(y^{b}, f^{b}\right) \in Y^{b} \times \mathbb{R}^{J}$. In every state $s \in\{0, \ldots, S\}$ the income $d_{s}^{b^{*}}$ is divided between the owners (consumers) of firm $b$ according to the specified shares $\theta^{a b}$.

At date $t=0$ the consumer $a \in A$ receives part of the income $d_{0}^{b}$ generated by firm $b$ and sells the initial endowment vector $\omega_{0}^{a} \in \mathbb{R}^{\ell}$ at the price vector of prices $p_{0} \in \mathbb{R}^{\ell}$. His initial income is equal to $p_{0} \omega_{0}^{a}+\sum_{b \in B} \theta^{a b} d_{0}^{b}$. He chooses the consumption plan $x_{0}^{a} \in X_{0}^{a}$ at price vector $p_{0} \in \mathbb{R}^{\ell}$ and purchases the portfolio $h^{a} \in \mathbb{R}^{J}$ at security prices $q \in \mathbb{R}^{J}$. Hence:

$$
p_{0} x_{0}^{a} \leq p_{0} \omega_{0}^{a}-q h^{a}+\sum_{b \in B} \theta^{a b} d_{0}^{b} .
$$

At date $t=1$ and state $s \in\{1, \ldots, S\}$ consumer $a$ pays $p_{s} x_{s}^{a}$ and receives income: $p_{s} \omega_{s}^{a}, V_{s} h^{a}$ and $\sum_{b \in B} \theta^{a b} d_{s}^{b}$. Hence:

$$
p_{s} x_{s}^{a} \leq p_{s} \omega_{s}^{a}+V_{s} h^{a}+\sum_{b \in B} \theta^{a b} d_{s}^{b} .
$$

Let the pair $\left(x^{a}, h^{a}\right) \in X^{a} \times \mathbb{R}^{J}$ denote the action plan of consumer $a$. Then the budget set of consumer $a$ is of the form:

$$
\beta(a)=\left\{\left(x^{a}, h^{a}\right) \in X^{a} \times \mathbb{R}^{J}: \begin{array}{l}
p_{0} x_{0}^{a} \leq p_{0} \omega_{0}^{a}-q h^{a}+\sum_{b \in B} \theta^{a b} d_{0}^{b} \\
p_{s} x_{s}^{a} \leq p_{s} \omega_{s}^{a}+V_{s} h^{a}+\sum_{b \in B} \theta^{a b} d_{s}^{b}, \quad s \in\{1, \ldots, S\}
\end{array}\right\} .
$$

If $\left(x^{a}, h^{a}\right) \in \beta(a)$, then portfolio $h^{a} \in \mathbb{R}^{J}$ finances the consumption plan $x^{a} \in X^{a}$. The system of inequalities at date $t=1$ can be written as the inequality:

$$
p\left(x^{1 a}-\omega^{1 a}\right)-\sum_{b \in B} \theta^{a b} d^{1 b} \leq V h^{a},
$$

where $x^{1 a}=\left(x_{1}^{a}, \ldots, x_{S}^{a}\right), \omega^{1 a}=\left(\omega_{1}^{a}, \ldots, \omega_{S}^{a}\right), d^{1 b}=\left(d_{1}^{b}, \ldots, d_{S}^{b}\right) \in \mathbb{R}^{S}$.

Thence, for $W=\left[\begin{array}{c}-q \\ V\end{array}\right]$ :

$$
\beta(a)=\left\{\left(x^{a}, h^{a}\right) \in X^{a} \times \mathbb{R}^{J}: p\left(x^{a}-\omega^{a}\right)-\sum_{b \in B} \theta^{a b} d^{b} \leq W h^{a}\right\} .
$$

Every consumer chooses an action plan $\left(x^{a^{*}}, h^{a^{*}}\right)$ that maximises its utility function subject to budget constraints. 
Let $\left(\left(x^{a^{*}}, h^{a^{*}}\right),\left(y^{b^{*}}, f^{b^{*}}\right)\right)$ be an allocation in economy $\varepsilon_{F}$, where $x=\left(x^{a}\right)_{a \in A}=$ $=\left(x^{1}, \ldots, x^{m}\right) \in\left(\mathbb{R}_{+}^{S+1}\right)^{m} ; h=\left(h^{a}\right)_{a \in A}=\left(h^{1}, \ldots, h^{m}\right) \in\left(\mathbb{R}^{J}\right)^{m} ; y=\left(y^{b}\right)_{b \in B}=$ $=\left(y^{1}, \ldots, y^{n}\right) \in\left(\mathbb{R}^{S+1}\right)^{n} ; f=\left(f^{b}\right)_{b \in B}=\left(f^{1}, \ldots, f^{n}\right) \in\left(\mathbb{R}^{J}\right)^{n}$. We can formally assume the following definition of equilibrium (see Magill \& Quinzii 2002).

Definition 2.2. The sequence $\left(\left(x^{a^{*}}, h^{a}\right),\left(y^{b^{*}}, f^{b^{*}}\right), p^{*}, q^{*}\right)$ satisfying the following conditions is called the state of equilibrium in economy $\varepsilon_{F}$ :

1) $\forall b \in B \quad\left(y^{b^{*}}, f^{b^{*}}\right) \in \arg \max \left\{\mu d^{b^{*}}:\left(y^{b}, f^{b}\right) \in Y^{b} \times \mathbb{R}^{J}\right\}$,

2) $\forall a \in A \quad\left(x^{a^{*}}, h^{a^{*}}\right) \in \arg \max \left\{u\left(x^{a^{a}}\right):\left(x^{a}, h^{a}\right) \in \beta(a)\right\}$,

3) $\forall s \in\{0, \ldots, S\} \quad \sum_{a \in A} x_{s}^{a^{*}}-\sum_{b \in B} y_{s}^{b^{*}}=\sum_{a \in A} \omega_{s}^{a}$,

4) $\sum_{a \in A} h^{a^{*}}+\sum_{b \in B} f^{b^{*}}=0 \in \mathbb{R}^{J}$.

\section{Innovations in the Economy with a Financial Market}

This part of the paper is devoted to modeling Schumpeter's vision of innovations in a private ownership economy with a financial market. The logical consequence of activities of economic agents in this economy is to distinguish two kinds of innovations: those on the real market (hereinafter real innovations) and those on the financial market (financial innovations). The real innovation is a new good (a source or a new product) or a new technology introduced on the real commodities market (see Lipieta \& Malawski 2016), while a financial innovation is a new security occurring on the financial market.

To distinguish innovations in an economy modeled as a private ownership economy with a financial market, we have to compare both producers' plans of action and investors' securities portfolios in two different dates $t_{0}$ and $t_{0}^{\prime}$, where $t_{0}<t_{0}^{\prime}$. Date $t_{0}$ is assumed to be the initial period for the private ownership economy with a financial market $\varepsilon_{F}=(u, \omega, Y, \theta, V)$ with $S$ states of nature considered at date $t_{1}$, where $t_{0}<t_{1}$. Similarly, dates $t_{0}^{\prime}$ and $t_{1}^{\prime}$, where $t_{1} \leq t_{0}^{\prime}<t_{1}^{\prime}$, denote the initial and the future date, adequately, of economy $\varepsilon_{F}^{\prime}=\left(u^{\prime}, \omega^{\prime}, Y^{\prime}, \theta^{\prime}, V^{\prime}\right)$ with $S^{\prime}$ states of nature at date $t_{1}^{\prime}$, To sum up, economy $\varepsilon_{F}^{\prime}$ models the activities of economic agents on the real markets and on the financial markets considered in economy $\varepsilon_{F}$. It may be therefore refered to the evolution of economy $\varepsilon_{F}$. This property will be denoted by $\varepsilon_{F} \subset \varepsilon_{F}^{\prime}$.

Let $\varepsilon_{F} \subset \varepsilon_{F}^{\prime}$. Following Schumpeter, it is assumed that:

1) the set of commodities in economy $\varepsilon_{F}$ are contained in the set of commodities of economy $\varepsilon_{F}^{\prime}$; hence $\ell \leq \ell^{\prime}$; 
2) the set of securities in economy $\varepsilon_{F}$ is contained in the set of securities of economy $\varepsilon_{F}^{\prime}$; hence $J \leq J^{\prime}$;

3) the set of producers and consumers in both economies $\varepsilon_{F}$ and $\varepsilon_{F}^{\prime}$ are the same, namely $A=A^{\prime}$ and $B=B^{\prime}$;

4) if $Y^{b}=\{0\} \subset \mathbb{R}^{\ell(S+1)}$ and $Y^{b b} \neq\{0\} \subset \mathbb{R}^{\ell^{\prime}\left(S^{\prime}+1\right)}$, then producer $b$ enters the markets at date $t_{0}^{\prime}$ or earlier, but after date $t_{1}$; if $Y^{b} \neq\{0\} \subset \mathbb{R}^{\ell(S+1)}$ and $Y^{\prime b}=\{0\} \subset \mathbb{R}^{\ell^{\prime}\left(S^{\prime}+1\right)}$, then producer $b$ exits the markets at date $t_{0}^{\prime}$ or earlier, but after date $t_{1}$; the same can be observed of consumers;

5) if $\varepsilon_{F} \subset \varepsilon_{F}^{\prime}$, where $t_{1}=t_{0}^{\prime}$, then $\ell=\ell^{\prime}$ and:

$$
\exists s \in\{1, \ldots, S\} \forall b \in B Y_{s}^{b}=Y_{0}^{\prime b} \text { and } \forall a \in A X_{s}^{a}=X_{0}^{\prime a} .
$$

Property 4 reflects the principle of creative destruction.

The next section introduces a number of essential definitions. Suppose that economy $\varepsilon_{F}$ is given.

Definition 3.1. An investment project $y^{\tilde{b}}=\left(y_{0}^{\tilde{b}}, \ldots, y_{s}^{\tilde{b}}\right) \in Y^{\tilde{b}}$ is called the innovative project of producer $\tilde{b}$ at date $t_{1}$ with respect to date $t_{0}$, if:

$$
\exists \tilde{l} \in\{1,2, \ldots, \ell\}:\left(\forall b \in B \quad y_{0, \tilde{l}}^{b}=0 \wedge \forall s \in\{1, \ldots, S\} y_{s, \tilde{l}}^{\tilde{b}} \neq 0\right)
$$

or

$$
\forall b \in B \forall s \in\{1, \ldots, S\} y_{s}^{\tilde{b}} \notin Y_{0}^{b} .
$$

If condition (5) is satisfied for a producer $\tilde{b} \in B$, then a new commodity $\tilde{l}$ is introduced by producer $\tilde{b}$ on the real market at date $t_{1}$. Commodity $\tilde{l}$ is the real innovation at date $t_{1}$ with respect to date $t_{0}$. Condition (6) means that the productive abilities of producer $\tilde{b}$ at date $t_{1}$ go beyond the technological possibilities of all producers at date $t_{0}$. The innovations in this case are the new technology revealed in the innovative investment project of producer $\tilde{b}$ at date $t_{1}$. Such innovativeness is called technological innovativeness, which falls into the category of innovations on the real market. Hence, if condition (6) is satisfied for producer $\tilde{b} \in B$, then it is also said that producer $\tilde{b}$ introduces an innovation at date $t_{1}$. Producer $\tilde{b}$ satisfying conditions (5) or (6) is called an innovator.

Consider two economies $\varepsilon_{F}$ and $\varepsilon_{F}^{\prime}$, where $\varepsilon_{F} \subset \varepsilon_{F}^{\prime}$.

Definition 3.2. An investment project $y^{\prime \tilde{b}}=\left(y_{0}^{\prime \tilde{b}}, \ldots, y_{s}^{\prime \tilde{b}}\right) \in Y^{\prime \tilde{b}}$ is called an innovative project of producer $\tilde{b}$ at date $\mathrm{t}_{0}^{\prime}$ with respect to economy $\varepsilon_{F}$, if:

$$
\ell<\ell^{\prime} \Rightarrow \forall b \in B \quad y_{0}^{\prime \tilde{b}} \notin\left(Y_{0}^{b} \times\{0\} \times \ldots \times\{0\}\right) \subset \mathbb{R}^{\ell^{\prime}},
$$


or

$$
\ell=\ell^{\prime} \Rightarrow \forall b \in B \quad y_{0}^{\prime \tilde{b}} \notin Y_{0}^{b} \subset \mathbb{R}^{\ell} .
$$

If condition (7) is satisfied for a producer $\tilde{b} \in B$, then every commodity $l \in\left\{\ell+1, \ldots, \ell^{\prime}\right\}$ is introduced on the real market at date $t_{0}^{\prime}$. It is the real innovation at this date with respect to economy $\varepsilon_{F}$. If condition (8) is valid, then the productive feasibilities of producer $\tilde{b}$ at date $t_{0}^{\prime}$ go beyond the technological possibilities of all producers at date $t_{0}^{\prime}$. The technological innovations are revealed in the innovative investment project of producer $\tilde{b}$ at date $t_{0}^{\prime}$ with respect to economy $\varepsilon_{F}$. Hence, if condition (8) is satisfied for a producer $\tilde{b} \in B$, then producer $\tilde{b}$ introduces innovations on the real market. Producer $\tilde{b}$ is the innovator.

Remark 3.1. Let $\varepsilon_{F} \subset \varepsilon_{F}^{\prime}$, where $t_{1}=t_{0}^{\prime}$. If an investment project $y^{\tilde{b}}=\left(y_{0}^{\tilde{b}}, \ldots, y_{s}^{\tilde{b}}\right) \in Y^{\tilde{b}}$ is the innovative project of producer $\tilde{b}$ at date $t_{1}$ with respect to date $t_{0}$, then the investment project $\left(y_{0}^{\prime \tilde{b}}, \ldots, y_{s}^{\prime \tilde{b}}\right) \in Y^{\prime \tilde{b}}$ is the innovative project with respect to economy $\varepsilon_{F}$.

Definition 3.3. If $\varepsilon_{F} \subset \varepsilon_{F}^{\prime}$ and

$$
J<J^{\prime},
$$

then every security $j \in\left\{J+1, \ldots, J^{\prime}\right\}$ is called an innovation on the financial market at date $t_{1}^{\prime}$.

Definitions 3.1-3.3 cover all kinds of innovations distinguished by J. A. Schumpeter.

\section{Mechanisms in the Economy with the Financial Market}

Here we recall Hurwicz's understanding of mechanisms (Hurwicz \& Reiter 2006). Let $E$ be the set of all characteristics of economic agents in a given structure/process. This is called the set of environments.

Definition 4.1. The triple $\Gamma=(M, \mu, h)$, where:

- the set $\mathrm{M} \neq \varnothing$, called the message space, contains the messages (signals) available to communications within agents,

- the correspondence $\mu: E \rightarrow M$, called the message correspondence, associates with each environment $e \in E$ the set of messages $\mu(e)$,

- the function $h: M \rightarrow Z$, called the outcome function, assigns the outcome $z \in Z$ to every message $m \in M$, is called the economic mechanism in the sense of Hurwicz. 
Definition 4.2. Mechanism $\Gamma$ is called the innovative mechanism, if the real or the financial innovations are components of the set of outcomes.

In the following theorem the mechanism, in which the set of environments consists of the characteristics of economic agents in the private ownership economy with a financial market, is defined. This mechanism in some cases is an innovative mechanism.

Theorem 4.1. Let $\varepsilon_{F}$ be the private ownership economy with a financial market, where consumption sets are compact, the utility functions are continuous and the condition:

$$
\sum_{a \in A} \omega^{a} \in\left(\left(X^{a_{1}} \times \ldots \times X^{a_{m}}\right)-\left(Y^{b_{1}} \times \ldots \times Y^{b_{n}}\right)\right)
$$

is satisfied. The process of determining the equilibrium in economy $\varepsilon_{F}$ is then a Hurwicz-type economic mechanism.

Proof. The proof of the theorem is standard and relies on defining the compositions of the economic mechanism in Hurwicz's sense. Let $\varepsilon_{F}=$ $=(u, \omega, Y, \theta, V)$, the private ownership economy with a financial market, be given. The environment of agent $k \in A \cup B$ is defined by the formula:

$$
e^{k}=\left(\tilde{Y}^{k}, \tilde{X}^{k}, \tilde{u}^{k}, \tilde{\omega}^{k}, \tilde{\theta}^{k}\right)
$$

where $\tilde{Y}^{k}=\left\{\begin{array}{l}Y^{k} \text { for } k \in B \\ \{0\} \text { for } k \notin B\end{array} ; \tilde{X}^{k}=\left\{\begin{array}{l}X^{k} \text { for } k \in A \\ \{0\} \text { for } k \notin A\end{array} ; \tilde{\omega}^{k}=\left\{\begin{array}{ll}\omega^{k} & \text { for } k \in A \\ 0 \in \mathbb{R}^{\ell} & \text { for } k \notin A\end{array}\right.\right.\right.$;

$\tilde{u}^{k}=\left\{\begin{array}{l}u^{k} \text { for } k \in A \\ 0 \text { for } k \notin A\end{array}\right.$.

The number $\tilde{\theta}^{k_{1} k_{2}}=0$, if $k_{1} \notin A$, or $k_{2} \notin B$ and $\tilde{\theta}^{k_{1} k_{2}}=\theta^{k_{1} k_{2}}$, if $k_{1} \in A$ and $k_{2} \in B$.

The set of all feasible environments of agent $k \in A \cup B$ form the set $E^{k}$. Denoting the number of all economic agents by $K$, the set of environments is given by $E=E^{1} \times \ldots \times E^{K}$.

Due to the aims of economic agents in the economy $\varepsilon_{F}$, the set of outcomes is of the form:

$$
Z \stackrel{\text { def }}{=}\left\{\begin{array}{c}
\left(\left(x^{a^{*}}, h^{a^{*}}\right),\left(y^{b^{*}}, f^{b^{*}}\right)\right): \exists p^{*} \in \mathbb{R}^{\ell}, q^{*} \in \mathbb{R}^{J} \\
\text { conditions }(1)-(4) \text { by Definition } 2.2 \text { are satisfied }
\end{array}\right\} .
$$


It is readily apparent that under the assumptions of the present theorem, set $Z$ is not empty. To conclude the proof, it is enough to define the set of messages, the message correspondence and the outcome function. The following yields the results. Put:

- the message space:

$$
M \stackrel{\text { def }}{=}\left\{\begin{array}{l}
\left(\left(x^{a}, h^{a}\right),\left(y^{b}, f^{b}\right), p, q\right): \sum_{a \in A} h^{a}-\sum_{b \in B} f^{b}=0 \wedge \\
\forall s \in\{0, \ldots, S\}: \sum_{a \in A} x_{s}^{a}-\sum_{b \in B} y_{s}^{b}=\sum_{a \in A} \omega_{s}^{a}
\end{array}\right\},
$$

- the message correspondence: $\mu(e) \stackrel{\text { def }}{=} \cap_{k \in A \cup B} \mu^{k}\left(e^{k}\right)$, where $\mu^{k}: E^{k} \rightarrow M$ is the message correspondence of agent $k \in A \cup B$, where:

$$
\begin{gathered}
k \in B \backslash A \Rightarrow \mu^{k}\left(e^{k}\right)=\left\{m \in M:\left(y^{b^{*}}, f^{b^{*}}\right) \in \arg \max \left\{\mu d^{b^{*}}:\left(y^{b}, f^{b}\right) \in Y^{b} \times \mathbb{R}^{J}\right\}\right\}, \\
k \in A \backslash B \Rightarrow \mu^{k}\left(e^{k}\right)=\left\{m \in M:\left(x^{a^{*}}, h^{a^{*}}\right) \in \arg \max \left\{u\left(x^{a^{*}}\right):\left(x^{a}, h^{a}\right) \in \beta(a)\right\}\right\}, \\
k \in A \cap B \Rightarrow \mu^{k}\left(e^{k}\right)=\{m \in M: \\
\left(y^{b^{*}}, f^{b^{*}}\right): \in \arg \max \left\{\mu d^{b^{*}}:\left(y^{b}, f^{b}\right) \in Y^{b} \times \mathbb{R}^{J}\right\} \wedge \\
\left.\left(x^{a^{*}}, h^{a^{*}}\right): \in \arg \max \left\{u\left(x^{a^{*}}\right):\left(x^{a}, h^{a}\right) \in \beta(a)\right\}\right\},
\end{gathered}
$$

- the outcome function:

$$
\left.h: M \rightarrow Z ; \quad h\left(\left(x^{a}, h^{a}\right),\left(y^{b}, f^{b}\right), p, q\right)\right) \stackrel{\text { def }}{=}\left(\left(x^{a}, h^{a}\right),\left(y^{b}, f^{b}\right)\right) .
$$

If one of the conditions (5) or (6) is satisfied, then the mechanism defined in Theorem 4.1 is the innovative mechanism.

In the next theorem the mechanism of evolution of the private ownership economy with a financial market is defined.

Theorem 4.2. If $\varepsilon_{F} \subset \varepsilon_{F}^{\prime}$, then the process of evolution of economy $\varepsilon_{F}$ into economy $\varepsilon_{F}^{\prime}$ is the economic mechanism as Hurwicz's conceptualised it.

Proof. The environment of every agent $k \in A \cup B$ is of the form (10). The outcome $z^{k}$ of every agent $k$ is given by components of economy $\varepsilon_{F}^{\prime}$ as it was given in the case of the environment of economic agents. That is, $z^{k}=\left(\tilde{Y}^{k}, \tilde{X}^{\prime k}, \tilde{u}^{\prime k}, \tilde{\omega}^{\prime k}, \tilde{\theta}^{\prime k}\right)$. The set $Z^{k}$ consists of the feasible outcomes of agent $k$. Consequently the set of outcomes is given by $Z=Z^{1} \times \ldots \times Z^{K}$. Keeping in mind the aims of economic agents in the process of evolution of the economy under study, it is defined, for every $k \in A \cup B, m^{k}=z^{k}$ and consequently $M^{k}=Z^{k}$ and $M=Z$. The set of environment $E^{k}$ of agent $k$ as well as the set of environment $E$ are defined in the same way as was done in 
the proof of Theorem 4.1. Finally, the outcome function $h: M \rightarrow Z$ is given by $h \stackrel{\text { def }}{=} i d_{M}$. The last one yields the result of the theorem.

If at least one of the conditions (7), (8) or (9) is satisfied, then the mechanism of the financial economy's evolution defined in the proof of Theorem 4.2 is the innovative mechanism.

In the following theorem, another mechanism connected to innovation is formulated.

Theorem 4.3. The private ownership economy with a financial market is the economic mechanism in Hurwicz's sense.

Proof. For $k \in A \cup B$ we define $e^{k}$ of the form (10) and $z^{k}=e^{k}$. The rest of the proof proceeds the same as the proof of Theorem 4.2.

The mechanism defined in Theorem 4.3 is called the structural mechanism. If one of the conditions (5) or (6) is satisfied, then the above structural mechanism is the innovative mechanism.

The following theorem concludes our analysis of innovative mechanisms in the economy.

Theorem 4.4. Let $\varepsilon_{F} \subset \varepsilon_{F}^{\prime}$, where $t_{1}=t_{0}^{\prime}$. If the structural mechanism of economy $\varepsilon_{F}$ is the innovative mechanism, then the mechanism of economy $\varepsilon_{F}$ 's evolution into economy $\varepsilon_{F}^{\prime}$ is also the innovative mechanism.

Proof. It is the immediate consequence of Remark 3.1.

\section{Conclusions}

Using a private ownership economy with a financial market in modeling the innovations as Schumpeter conceived them enables to determine and to estimate the sources of funding of innovation - that is, the producers' profits, and income from the sale of financial securities and easily accessible credits. This approach corresponds with Schumpeter's concept of economic development.

Using the idea of the Hurwicz's economic mechanism reveals a very close relationship between signals sent by economic agents and their aims on the markets in conditions of perfect competition.

The mechanisms defined in the paper often have qualitative properties, especially if introducing innovation leads to an increase in profits or utility. If that occurs, the position of an adequate group of economic agents may be said to have improved (see Innovative Economy... 2013, Chapter 4). 
Given the above, innovations in the economy with a financial market as well as innovative mechanisms in this economy would appear to merit further study.

\section{Bibliography}

Ciałowicz, B. and Malawski, A. (2011) "The Role of Banks in the Schumpeterian Innovative Evolution: An Axiomatic Set-up" in A. Pyka, M. da Graça Derengowski Fonseca (eds), Catching up, Spillovers and Innovations Networks in a Schumpeterian Perspective. Heidelberg-Dordrecht-London-New York: Springer.

Ćwięczek, I., Lipieta, A. and Malawski, A. (2012) "Dwuokresowy model dochodu jako mechanizm ekonomiczny w ujęciu Hurwicza" [The two-period income model as Hurwicz's economic mechanism]. Zeszyty Naukowe Polskiego Towarzystwa Ekonomicznego 12: 9-20.

Debreu, G. (1959) Theory of Value. New York: Wiley.

Hurwicz, L. and Reiter, S. (2006) Designing Economic Mechanism. New York: Cambridge University Press.

Innovative Economy as the Object Investigation in Theoretical Economics (2013) ed. A. Malawski. Cracow: Cracow University of Economics Press.

Lipieta, A. and Malawski, A. (2016) "Price versus Quality Competition: In Search for Schumpeterian Evolution Mechanisms". Journal of Evolutionary Economics 26 (5): 1137-71, https://doi.org/10.1007/s00191-016-0470-8.

Magill, M. and Quinzii, M. (2002) Theory of Incomplete Markets. Cambridge: MIT Press.

Malawski, A. (1999) Metoda aksjomatyczna w ekonomii [The axiomatic method in economics]. Wrocław: Ossolineum.

Schumpeter, J. A. (1912) Die Theorie der wirtschaftlichen Entwicklung. Leipzig: Duncker \& Humblot; English edition: The Theory of Economic Development. New York: Oxford University Press, 1961.

\section{Abstract}

\section{Mechanizmy innowacyjne w ekonomii z własnością prywatną i rynkiem finansowym}

W ekonomii $\mathrm{z}$ własnością prywatną i rynkiem finansowym innowacje w ujęciu Schumpetera można opisać w topologicznym aparacie pojęciowym Arrowa i Debreu, dzięki czemu uwidacznia się wpływ wzajemnych powiązań między rynkami realnym i finansowym na procesy innowacyjne.

Celem artykułu jest modelowanie innowacji i różnych rodzajów mechanizmów innowacyjnych ujawniających się $\mathrm{w}$ procesie schumpeterowskiej ewolucji. Zastosowanie hurwiczowskiego aparatu pojęciowego sprawia, że główne rezultaty przybierają postać twierdzeń matematycznych interpretowanych w języku ekonomii.

Słowa kluczowe: schumpeterowska ewolucja, mechanizmy ekonomiczne, projektowanie mechanizmów ekonomicznych, ekonomia z rynkiem finansowym. 